\section{Case series of cutaneous Langerhans cell histiocytosis in Indonesian children; The clinicopathological spectrum}

\author{
Irianiwati Widodo, Nita Sahara, \\ Ery Kus Dwianingsih, \\ Paranita Ferronika
}

Department of Anatomical Pathology, Faculty of Medicine, Public Health and Nursing, Universitas Gadjah Mada, Yogyakarta, Indonesia.

\begin{abstract}
Langerhans Cell Histiocytosis (LCH) is a rare disease characterized by the clonal proliferation of Langerhans cells, which are immunoreactive to $\mathrm{S}-100$ and CD-1a/ CD207 (Langerin). Cutaneous involvement is the most common presentation of $\mathrm{LCH}$ in children. It is suggested that the patients with single-system LCH limited to the skin have a better prognosis than those with systemic involvement. Three histologic reactions of cutaneous LCH have been reported and are associated with the clinical types of $\mathrm{LCH}$. These histological reactions include: proliferative, granulomatous, and xanthomatous. This study presents the clinicopathological features of ten cutaneous LCH cases collected from Dr. Sardjito General Hospital Yogyakarta Indonesia between 2014-2018. The ten cases showed various clinical features, in which some features mimic other diseases. The microscopic features of skin biopsies showed granulomatous reaction in $80 \%$ of cases and proliferative reaction in the other $20 \%$. Five patients ( $50 \%$ of cases) who died had systemic manifestation of thrombocytopenia, anemia, icterus, hepatosplenomegaly, and revealed the granulomatous type from their skin biopsy specimens. The clinical recognition of LCH and subsequent histological reaction determination are important since some cases may develop multisystem disease and have a poor prognosis.
\end{abstract}

\section{Introduction}

Langerhans Cell Histiocytosis ( $\mathrm{LCH})$ is a disease characterized by the clonal proliferation of abnormal Langerhans cells in one or multiple organs. ${ }^{1}$ Based on the extent and severity of the disease, LCH may clinically manifest in three different forms. ${ }^{2}$ The first and the most common form is eosinophilic granuloma, a localized benign LCH which is restricted to bone ${ }^{3}$ The second form is Letterer-Siwe disease which has multiple organ involvement such as diabetes insipidus and osteolytic skull lesions. ${ }^{4}$ The third form is the Hand-Schuller-Christian disease, which is aggressive and leads to multisystem involvement. ${ }^{5}$ Although the exact cause of LCH is unclear, the somatic mutations in RAS-ERK pathways, especially involving the BRAF-V600E gene have been identified to have a role in the pathogenesis of this disease. ${ }^{6,7}$

Langerhans cell histiocytosis can affect a wide age range including neonates, young children and adults. In children younger than two years of age, most LCH cases are presented with cutaneous involvement. This cutaneous presentation is referred to as cutaneous $\mathrm{LCH}$, and is uncommon in adults. The incidence rate of $\mathrm{LCH}$ in children is approximately 2-9 cases in a million-general population per year., ${ }^{6,7}$ The number of affected males is slightly higher than females.

Cutaneous LCH has various clinical manifestations which may mimic other skin diseases. It may resemble seborrheic dermatitis which mostly occurs on the scalp and show erythematous papular rash or nodular ulcerative lesions. Cutaneous LCH may also show skin petechiae, erythematous vesicopustules with crusts, plaques and nodules. The similarities of cutaneous LCH with some other skin diseases may lead to misdiagnosis. ${ }^{7-9}$

Histological examination of cutaneous LCH may show atypical large cells with pale cytoplasm and reniform nucleus. ${ }^{10}$ Those atypical cells form dense dermal infiltrates and intraepidermal aggregates. Immunohistochemical staining of S-100 and CD1a or CD207 (Langerin) will show positive results in the atypical Langerhans cell. $^{2}$ Electron microscopic examination may show the presence of Birbeck granules. ${ }^{6}$

The histological reactions of cutaneous $\mathrm{LCH}$ are classified into three types: proliferative, granulomatous and xanthomatous. ${ }^{8,10,11}$ The proliferative type is characterized by extensive infiltrates of histiocytes close to or within the epidermis, which may result in ulceration and crusting. The granulomatous type shows the aggregates of histiocytes and clusters of eosinophils extending deep into the dermis. The xanthomatous type shows numerous foam cells along with histiocytes and eosinophils. The histological reaction type was suggested to be associated with the clinical type of LCH. ${ }^{10}$

The prognosis in LCH depends on the age of the patients, the extent of the disease and the presence of organ dysfunction. Most cutaneous LCH cases resolve sponta-
Correspondence: Irianiwati Widodo, Department of Anatomical Pathology

Faculty of Medicine, Public Health and Nursing, Universitas Gadjah Mada

Jl. Kesehatan Sekip Yogyakarta 55281, Indonesia

Tel.: +62274 540460

E-mail: irianiwati@ugm.ac.id

Key words: cutaneous Langerhans cell histiocytosis; children; clinicopathological features.

Acknowledgement: We thank the staff of Klinik Bahasa, Universitas Gadjah Mada for editorial advice.

Conflict of interest: the authors declare no potential conflict of interests.

Presentation: The paper has been presented as a poster in Surgical Pathology Course, National University Health System, Singapore, 2 - 3 May 2019.

Received for publication: 5 July 2020

Accepted for publication: 23 September 2020.

This work is licensed under a Creative Commons Attribution-NonCommercial 4.0 International License (CC BY-NC 4.0).

${ }^{\circ}$ Copyright: the Author(s), 2020

Licensee PAGEPress, Italy

Dermatology Reports 2020; 12:8777

doi:10.4081/dr.2020.8777

neously and have a good prognosis, while the LCH with multisystem involvement can be life-threatening. Children younger than two years of age with multisystem organ disease and organ dysfunction have a mortality risk of $50 \%$ or more. ${ }^{6,7}$ This study aimed to present the clinicopathological spectrum of ten Indonesian cutaneous LCH cases in children which show various clinical manifestations that mimic other diseases. The early recognition of clinical and histopathological features of LCH is a key role to determine proper management of patients and predict the prognosis.

\section{Case Report}

Formalin-fixed paraffin-embedded tissues of Langerhans Cell Histiocytosis $(\mathrm{LCH})$ were collected from the Anatomical Pathology Laboratory, Dr. Sardjito General Hospital Yogyakarta from year 2014 to 2018. Hematoxylin and eosin sections, along with CD-1a and S100 immunostained slides were examined to confirm the diagnosis of LCH. Clinical information including age, gender, sites of disease were retrieved from the patients' medical records. 
Clinicopathological features of the cases were qualitatively analyzed.

Twenty cases of $\mathrm{LCH}$ were collected and confirmed by $\mathrm{S} 100$ and CD-1a immunostaining. Ten out of twenty $(50 \%)$ cases collected were cutaneous LCH and involved children (Table 1). The mean age of cutaneous LCH patients was 24.4 months (range 4-48 months). The cutaneous LCH occurred more frequently in boys $(60 \%)$ compared to girls (40\%). The most common clinical manifestations found in the ten cases were diffuse erythematous maculopapular lesions (5 patients), followed by seborrheic dermatitis lesions (3 patients), tinea lesions (1 patient) and inflammatory papules with pustules and excoriation mimicking cutaneous miliary tuberculosis (1 patient). The lesions developed on the skin of the patients' scalp, face, chest, back, groin, inguinal, abdomen and extremities (Figure 1). Among the eight patients clinically diagnosed with cutaneous LCH, five of them had differential diagnosis of miliary cutaneous tuberculosis, papulonecrotic tuberculid, tinea capitis, seborrheic dermatitis and leukemia cutis. The main clinical diagnosis of the other three patients was seborrheic dermatitis. Multisystem involvement of liver and bone marrow was found in five patients, accompanied with hepatosplenomegaly, icterus, anemia, thrombocytopenia and multiple lymphadenopathy. All patients with this multisystem involvement were deceased.
Histopathological diagnosis was established based on morphologic features of hematoxylin and eosin staining as well as immunostaining results of S100 and CD1a. Among the ten cases of cutaneous LCH studied, the granulomatous reaction type was found in eight cases $(80 \%)$, while the proliferative type was found in the other two cases $(20 \%)$. None of our LCH cases showed xanthomatous reaction. In the cases with granulomatous type, histiocytic aggregates along with eosinophil cells extended to the dermis
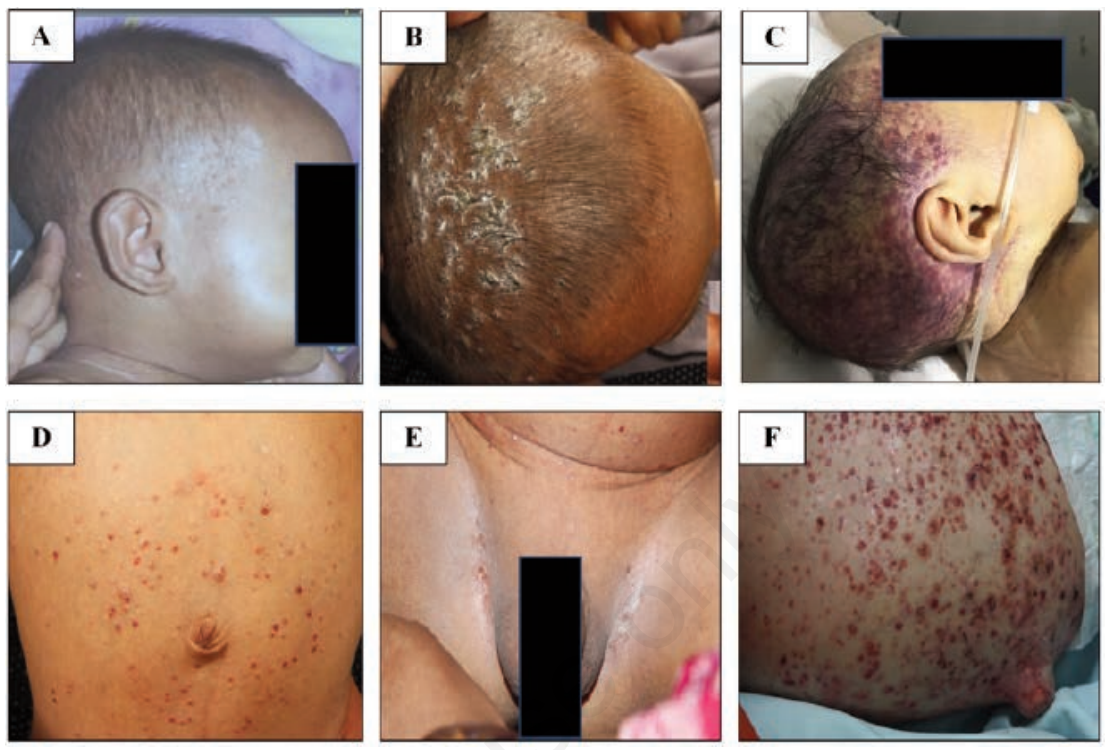

Figure 1. Various clinical manifestations of patients with cutaneous Langerhans cell histiocytosis. The scalp of different patients showing seborrheic dermatitis-like lesions, which are characterized by multiple perifollicular erythematous macules and patches (A), some with crusts $(B)$ and hemorrhages $(C)$. The abdomen showing multiple erythematous papules covered by crusts resembling cutaneous miliary tuberculosis (D). The groin showing erythematous papules with pustules and crusts resembling candidiasis (E). The abdomen showing erythematous macules and patches covered by crusts and hemorrhages $(\mathrm{F})$.

Table 1. Clinical and pathological features of ten cases of cutaneous Langerhans cell histiocytosis.

\begin{tabular}{|c|c|c|c|c|c|c|}
\hline No & Sex & $\begin{array}{l}\text { Age at } \\
\text { diagnosis } \\
\text { (months) }\end{array}$ & $\begin{array}{l}\text { Presenting } \\
\text { symptoms }\end{array}$ & $\begin{array}{l}\text { Histological } \\
\text { reaction } \\
\text { type }\end{array}$ & $\begin{array}{l}\text { Organ involved } \\
\text { besides skin }\end{array}$ & Status \\
\hline 1 & M & 15 & $\begin{array}{c}\text { Diffuse erythematous } \\
\text { maculo-papular lesion } \\
\text { and papulo-necrotic lesion }\end{array}$ & Granulomatous & $\begin{array}{c}\text { Hepatosplenomegaly, } \\
\text { bone marrow }\end{array}$ & Dead \\
\hline 2 & M & 42 & $\begin{array}{l}\text { Diffuse erythematous } \\
\text { maculo-papular lesion }\end{array}$ & Granulomatous & $\begin{array}{l}\text { Hepatosplenomegaly, } \\
\text { multiple lymphadenopathy }\end{array}$ & Dead \\
\hline 3 & M & 24 & $\begin{array}{l}\text { Diffuse erythematous } \\
\text { maculo-papular lesion }\end{array}$ & Granulomatous & Hepatosplenomegaly, bone marrow & Dead \\
\hline 4 & $\mathrm{~F}$ & 48 & $\begin{array}{l}\text { Diffuse erythematous } \\
\text { maculo-papular lesion }\end{array}$ & Granulomatous & $\begin{array}{l}\text { Hepatosplenomegaly, } \\
\text { multiple lymphadenopaty }\end{array}$ & Dead \\
\hline 5 & M & 18 & $\begin{array}{l}\text { Erythematous papules } \\
\text { with scale and crust on the head }\end{array}$ & Proliferative & No & Alive \\
\hline 6 & $\mathrm{~F}$ & 4 & $\begin{array}{c}\text { Extensive scaly } \\
\text { erythematouspatches } \\
\text { on the scalp }\end{array}$ & Granulomatous & no & Alive \\
\hline 7 & $\mathrm{~F}$ & 18 & Erythematous papular lesion & Proliferative & no & Alive \\
\hline 8 & M & 24 & $\begin{array}{l}\text { Diffuse erythematous } \\
\text { maculo-papular lesion }\end{array}$ & Granulomatous & $\begin{array}{l}\text { Hepatosplenomegaly, } \\
\text { bone marrow }\end{array}$ & Dead \\
\hline 9 & M & 27 & $\begin{array}{l}\text { Extensive scaly erythematous } \\
\text { patches on the scalp }\end{array}$ & Granulomatous & Hepatomegaly & Loss of follow up \\
\hline 10 & $\mathrm{~F}$ & 24 & $\begin{array}{l}\text { Inflammatory papules with } \\
\text { pustule and excoriation }\end{array}$ & Granulomatous & No & Loss of follow up \\
\hline
\end{tabular}


(Figure 2). Meanwhile, in those with the proliferative type, histiocytic proliferation involved the epidermis and formed ulcerations and crusts there (Figure 3 ).

\section{Discussion}

Cutaneous LCH occurs in around 33\% of all LCH cases in which crusts, scaly papules or papulovesicles are its common presentations. $^{12}$ The variability in skin presentations of $\mathrm{LCH}$ contributes to the frequent delay in accurate diagnosis. ${ }^{13}$ A number of cutaneous $\mathrm{LCH}$ cases in this study were previously misdiagnosed as seborrheic dermatitis, tinea lesion, cutaneous miliary tuberculosis and leukemia cutis. The cutaneous manifestation of extensive reddish scaly patches on the scalp was confused with the signs of seborrheic dermatitis. The erythematous papular rash was similar to tinea or candida lesions. The features of inflammatory papules with pustules and excoriation were thought to belong to cutaneous miliary tuberculosis. Similarly, papulonecrotic lesions were previously recognized as cutaneous leukemia.

The microscopic examinations of skin biopsies from the ten cutaneous LCH cases showed more granulomatous reaction type than the proliferative type. Our results differ from a previous study which found proliferative reaction type was more common than the granulomatous type. ${ }^{8}$ Granulomatous reaction type is usually present in singlesystem with a chronic focal or multifocal LCH. ${ }^{10}$ Meanwhile, the proliferative type is usually present with an acute disseminated multisystem LCH. ${ }^{14}$ However, this histopathological appearance cannot predict the clinical outcome of patients with $\mathrm{LCH} .{ }^{15}$ In our case series more LCH cases with granulomatous type have multisystem involvement than the proliferative type (Table 1). The inconsistent results between our case series and previous reports ${ }^{10,14}$ regarding the relation between histopathological subtypes and clinical findings might highlight inadequacy of histopathological analysis alone to define patients' clinical outcome.

The number of organs involved and the presence of risk organ involvement are more essential to determine the prognosis of $\mathrm{LCH}$ than the histopathological subtypes. ${ }^{15,16}$ Of patients with cutaneous LCH, $87-93 \%$ have other organ involvement including bone, pituitary, liver, spleen, hematopoietic system, lungs, lymph nodes, and the central nervous system. ${ }^{12}$ Among these organs, the involvement of liver, spleen, and bone marrow leads to a lower 5- year overall survival rates of the patients, thus it is considered as high-risk LCH. ${ }^{16}$

In the present case series study, five out of ten patients $(50 \%)$ were considered as high-risk LCH, which involved the skin, liver, spleen, lymph nodes and bone mar-
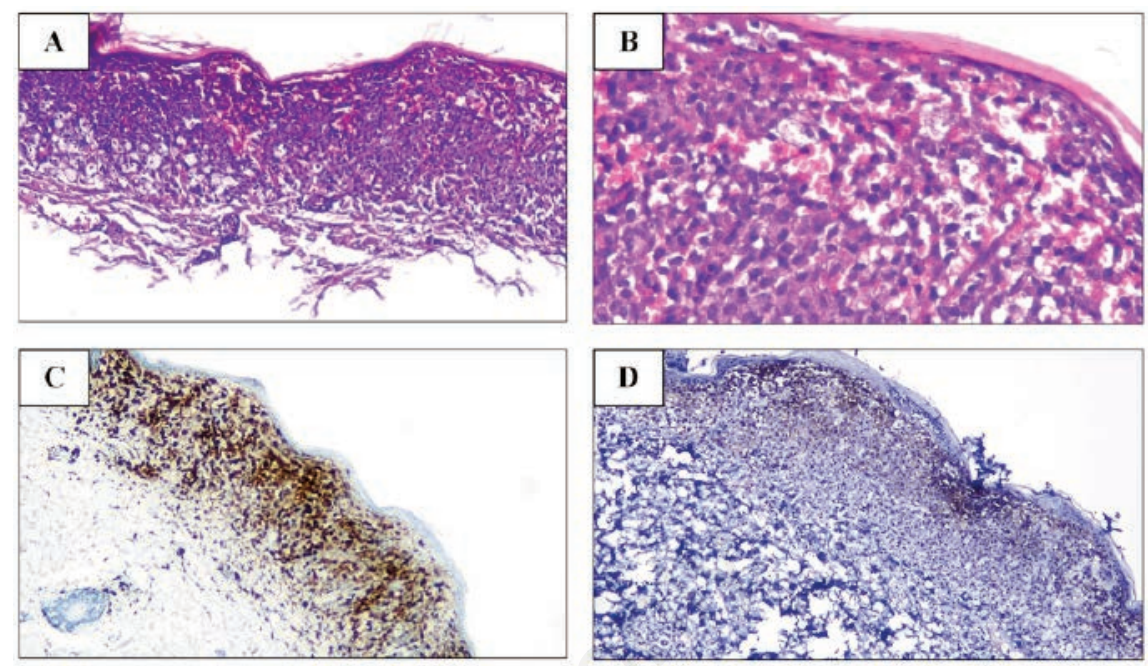

Figure 2. Histological pictures of granulomatous type cutaneous Langerhans cell histiocytosis. Skin biopsy from the chest was submitted to $H \& E$ staining. A. $100 x$ and B. 400x magnification views of epidermis and dermis showing histiocytic aggregates extending to dermis. The same paraffin block was submitted to immunohistochemistry for assessment of Langerhans cell expression marker. The 100x magnification views of $S 100$ (C) and CD1a (D) immunostained slides showing positive staining of the proliferative histiocytes extending to the dermis.
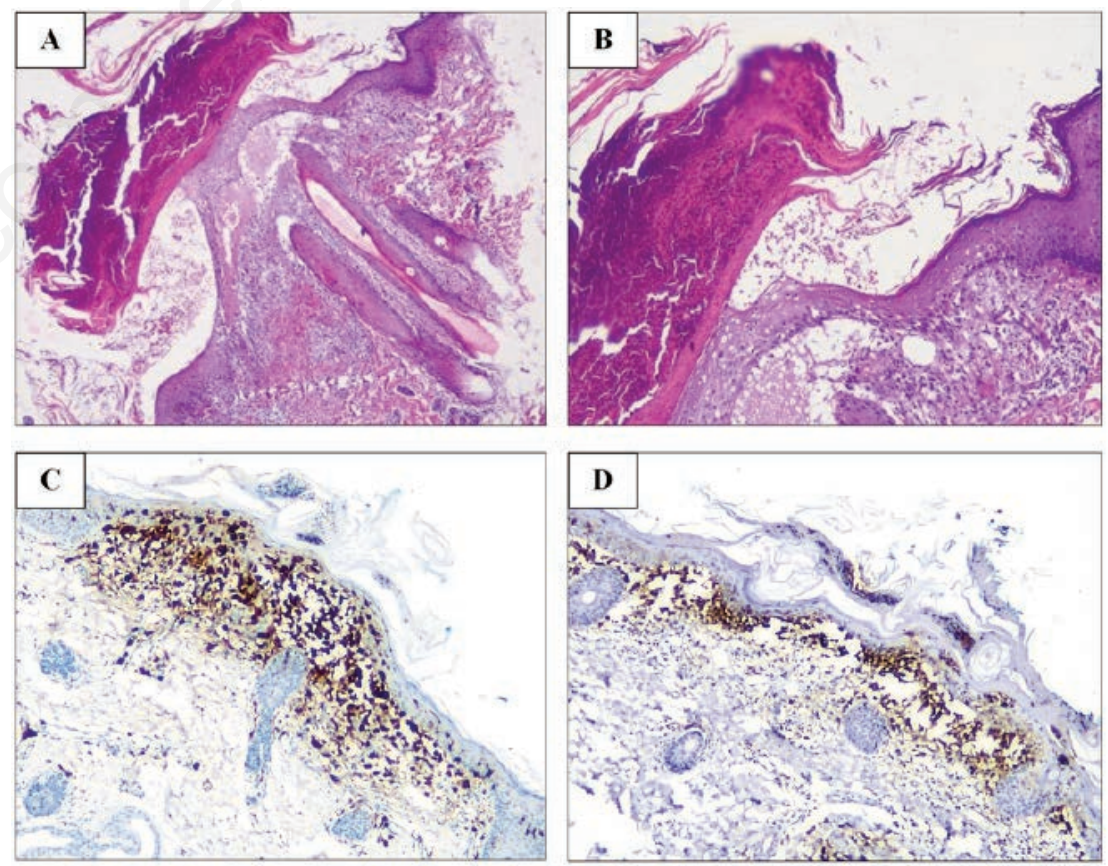

Figure 3. Histological pictures of proliferative type cutaneous Langerhans cell histiocytosis. Skin biopsy from the scalp was submitted to H\&E staining. A. $40 \mathrm{x}$ and B. 100x magnification views of epidermis and dermis showing histiocytic proliferation involved the epidermis forming ulceration and crusts. The same paraffin block was submitted to immunohistochemistry for assessment of Langerhans cell expression marker. The 100x magnification views of $S 100$ (C) and CD1a (D) immunostained slides showing positive staining of proliferative histiocytic cells in the upper dermis and epidermis. 
row. All those five patients were deceased. The severe form of $\mathrm{LCH}$ involving multiple organs can progress quickly and lead to $15 \%$ of therapeutic failure. ${ }^{17}$ Most $\mathrm{LCH}$ patients with organ involvement other than bone marrow, spleen and liver can be easily cured. The liver and spleen involvement may cause massive hepato-splenomegaly and liver dysfunction. This liver dysfunction causes hypoproteinemia which manifests in swelling of the extremities or abdomen, and also jaundice. LCH may also affect the lymph nodes, especially cervical, axillary, and inguinal lymph nodes. ${ }^{7}$ Bone marrow involvement clinically manifests as anemia, thrombocytopenia or leucopenia. ${ }^{6}$

The knowledge concerning the nature of LCH is still incomplete. Among reported LCH cases, somatic mutations are commonly found in BRAF-V600E (47.1\%), $M A P 2 K 1$ (21.7\%) and uncommonly found in $M A P 3 K 1$ or $A R A F .{ }^{18}$ The mutually exclusive mutations involving various genes in the RAS-ERK pathways suggest an over activation of ERK leading to high proliferation of neoplastic LCs. Cutaneous manifestation of LCH was found to be associated with BRAF-V600E mutation in $77.0 \%$ of children patients. ${ }^{19}$

Previous studies showed that the presence of circulating cells carrying $B R A F$ $V 600 E$ mutation is associated with a highrisk $\mathrm{LCH} .{ }^{7,18}$ The presence of circulating cells with BRAF-V600 mutation was also associated with a two-fold increase in the risk of $\mathrm{LCH}$ recurrence. ${ }^{7}$ Hematopoietic cell progenitors with $B R A F-V 600 E$ mutation were also identified in patients with highrisk $\mathrm{LCH} .{ }^{20}$ Unfortunately, BRAF mutation status was not examined in our $\mathrm{LCH}$ patients.

The stage of dendritic cells when the mutation occurs will determine the type of disease development. ${ }^{20}$ Mutation which occurs when the dendritic cells are still in the stem cell stage may facilitate the migration of early precursor cells to the liver, spleen and bone marrow. Mutation of mature dendritic cells may promote the migration of LCs to various organs but not to the liver spleen and bone marrow. Among previously observed cases, more mature dendritic cells carrying mutations have been found migrating only to skin and bone.

\section{Conclusions}

This report emphasizes the importance of a comprehensive analysis of clinical findings, histological features and immunohistochemical results (S100 and CD-1a) to confirm the diagnosis of cutaneous LCH. Cutaneous LCH in children which shows multisystem involvement and a granulomatous reaction type tend to have a poor prognosis in this case series.

\section{References}

1. Hussein MR. Skin-limited Langerhans' cell histiocytosis in children. Cancer Invest 2009;27:504-11.

2. Querings K, Starz H, Balda BR. Clinical spectrum of cutaneous Langerhans' cell histiocytosis mimicking various diseases. Acta Derm Venereol 2006;86:39-43.

3. Park SH, Park J, Hwang JH, et al. Eosinophilic granuloma of the skull: a retrospective analysis. Pediatr Neurosurg 2007;43:97-101.

4. Lam S, Reddy GD, Mayer R, et al. Eosinophilic granuloma/Langerhans cell histiocytosis: pediatric neurosurgery update. Surg Neurol Int 2015;6:S435-9.

5. Cassarino D, Dadras S. Diagnostic Pathology, Neoplastic Dermatopathology 2nd ed. Philadelphia: Elsevier; 2017.

6. Jezierska M, Stefanowicz J, Romanowicz G, et al. Langerhans cell histiocytosis in children - a disease with many faces. Recent advances in pathogenesis, diagnostic examinations and treatment. Postepy Dermatol Alergol 2018;35:6-17.

7. Simko SJ, Garmezy B, Abhyankar H, et al. Differentiating skin-limited and multisystem Langerhans cell histiocytosis. J Pediatr 2014;165:990-6.

8. Punia RS, Bagai M, Mohan H, Thami GP. Langerhans cell histiocytosis of skin: a clinicopathologic analysis of five cases. Indian J Dermatol Venereol Leprol 2006;72:211-4.

9. Utsav S, Geng S. Cutaneous langerhans cell histiocytosis: report of two cases.
Am J Case Rep 2011;12:154-8.

10. Elder D, Elenitsas R, Rubin A, et al. Atlas and synopsis of Lever's histopathology of the skin 3rd ed. Philadelphia: Lippincott Wlliam \& Wilkins; 2013.

11. Schmidt S, Eich G, Hanquinet S, et al. Extra-osseous involvement of Langerhans' cell histiocytosis in children. Pediatr Radiol 2004;34:313-21.

12. Haupt R, Minkov M, Astigarraga I, et al. Langerhans cell histiocytosis ( $\mathrm{LCH})$ : guidelines for diagnosis, clinical workup, and treatment for patients till the age of 18 years. Pediatr Blood Cancer 2013;60:175-84.

13. Stein SL, Paller AS, Haut PR, Mancini AJ. Langerhans cell histiocytosis presenting in the neonatal period: a retrospective case series. Arch Pediatr Adolesc Med 2001;155:778-83.

14. Leung AKC, Lam JM, Leong KF. Childhood Langerhans cell histiocytosis: a disease with many faces. World J Pediatr 2019;15:536-45.

15. Patterson J. Weedon's Skin Pathology 4 th ed. London: Churchill Livingstone Elsevier; 2016.

16. Krooks J, Minkov M, Weatherall AG. Langerhans cell histiocytosis in children: history, classification, pathobiology, clinical manifestations, and prognosis. J Am Acad Dermatol 2018;78:103544.

17. Allen CE, Ladisch S, McClain KL. How I treat Langerhans cell histiocytosis. Blood 2015;126:26-35.

18. Tran G, Huynh TN, Paller AS. Langerhans cell histiocytosis: a neoplastic disorder driven by Ras-ERK pathway mutations. J Am Acad Dermatol 2018;78:579-90.e4.

19. Heritier S, Emile JF, Barkaoui MA, et al. BRAF mutation correlates with high-risk Langerhans cell histiocytosis and increased resistance to first-line therapy. J Clin Oncol 2016;34:3023-30.

20. Berres ML, Merad M, Allen CE. Progress in understanding the pathogenesis of Langerhans cell histiocytosis: back to Histiocytosis X? Br J Haematol 2015;169:3-13. 